\title{
Legal Research Methodologies in European Union \& International Law: Research Notes (Part 1)
}

\section{Tamara Hervey, Rob Cryer \& Bal Sokhi-Bulley}

$\begin{array}{ll}\text { Project: } & \text { Collaborative Doctoral Training Project (ID 06/160/S) } \\ \text { Dates: } & \text { 1 October } 2006 \text { - 30 September } 2008 \\ \text { Project Leaders: } & \begin{array}{l}\text { Tammy Hervey (Professor of Law, University of Sheffield) } \\ \text { Rob Cryer (Professor of Law, University of Birmingham) } \\ \text { Bal Sokhi-Bulley (PhD Candidate, University of Nottingham) } \\ \text { Funding: }\end{array} \quad \text { Arts and Humanities Research Council (AHRC) }\end{array}$

\section{Introduction}

"Why do I need theory - my PhD is complex enough without it?"

"Where can I find ideas about what to do to solve my research problems?"

"I'm not a theorist -what's the point in theory unless it is useful for my specific research project?"

"What is a legal research methodology anyway?"

"How can I help my PhD students to devise and successfully complete their PhD projects?"

THESE KINDS OF QUESTIONS ARE THE RATIONALES BEHIND THIS AHRC funded research project and its two workshops (29-30 June 2007, University of Nottingham; 27-28 June 2008, University of Sheffield). The research project has two aims. The more directly substantive pedagogical aim is to enhance the methodological understandings and capabilities of three groups of scholars working in EU and international law: PhD students, staff at the early stages of their research careers, and more established members of staff who are PhD supervisors. The other core aim, based more on transferable skills and professional capacities, is to enable those PhD students to present their work and develop their networks with a wider range of scholars than in their home institution. 


\section{The Background to the Project and its Aims}

The project arose from the experiences of its coordinators. Law PhD students required to follow a module on Legal Research Methods seemed to fall into two distinct camps: the 'theory people' and 'the rest'. To generalise, this latter group seemed to feel that theory is the arcane preserve of a small group of self-identified theorists, and thus external to what most law PhD students or other academics do. But experience of teaching about legal research methods and supervising students led to an increasing conviction that theory (or methodology) is fundamentally practical. It relates directly to the formation of research projects, and then the practicalities of carrying out research - what research questions we ask, what data we use, how we carry out our research, how we explain why we examined what we did, or why we went about it in a particular way.

By 'methodology', we mean something different from, although related to, 'method'. The method is the way in which a research project is pursued - what a researcher actually does to enhance our knowledge, test her thesis, or answer her research question. Methodology is the system of methods applicable to research in a particular field, in this instance, international or EU law. Thus, methodology is closely related to what we understand the field of enquiry ((international or EU) law) to be. It is therefore closely related to questions of theory. To put it very crudely, and to give an example, if we believe law to be the written product of deliberations and negotiations between specific institutions (let us say, on the EU side, the European Commission, European Parliament and Council of Ministers, or, on the international side, multilateral treaty negotiations), then our system of methods - our methodology - for researching law in that sense will involve the analysis of the texts produced through those deliberations and negotiations. It will not be interested in the effects that law has on social life. Thus 'theory' and 'methodology' are closely bound up together. They inform the overall 'approach' that research projects take.

The project coordinators also noticed that law students in general tend to be less methodologically self-aware, less good at articulating the approach underpinning their projects or proposed projects, than those in other social science disciplines. For individual $\mathrm{PhD}$ students, this can pose problems at viva voce examinations, which often involve questions that are essentially about methodology, such as - why did you choose this project, what is important about it? Reflecting on this kind of question requires us to be explicit about the theoretical assumptions about the nature and qualities of law in general - and EU and international law to be more specific - that we make when setting out on our projects. Our assumptions, our approaches underpin the kind of legal research questions that we each think are valid or interesting. They also inform what we do when we are carrying out our research. Many law PhD students seem to lack the vocabulary and confidence to explore these matters - although they had often embarked upon, or even completed, worthwhile, interesting projects. At a disciplinary level, at a time when the RAE is moving towards some kind of metrics-based approach, albeit with continued peer review, the imperative for legal scholars to successfully attract funding for their research projects is becoming increasingly pressing. The project therefore also aims to provide an intellectual space within which EU and international law scholars can reflect on the unique contribution to the academy of legal research methodologies.

The project therefore aims to assist PhD students working in EU and international law to complete their projects, and become better equipped for their future careers as legal researchers. But the methodological development of a discipline is a matter for all its scholars, not simply a professional building block that we pick up early in our careers and then never revisit. The project is therefore also aimed at its coordinators, and their peers, 
other colleagues who work in EU and international law. The project is not principally aimed at the 'theory people', although they play a crucial role in the project's success, not least by assisting 'the rest' to embrace the theoretical, for instance, by articulating it in non-excluding language.

\section{The Project Process}

The project has two components: a set of materials and a series of workshops (the project coordinators hope that the partner institutions will continue to support the workshops from their research training funds beyond the life of the project). The materials form the basis of the workshop, and workshop participants must read the materials and consider the questions they raise, in the context of their own research projects, in advance of the workshop. The project thus began with the creation of the materials.

The project coordinators - two professors of law and a law PhD student - are responsible for the project materials. The materials were circulated to academic staff in the partner institutions for comment, and were substantially revised following that constructively critical process. At present, the materials are still a 'work in progress', in that they will be modified again in response to the experience of the workshops. The materials seek to provide a list of approaches (or methodologies) that are used in EU or international law scholarship, along with a brief introduction to each approach and two sample readings which either explain it or demonstrate its use - one in EU law and one in international law. The approaches (at present) consist of the following':

I. The Main Jurisprudential Approaches

A. Natural law

B. Legal positivism

II. Extensions and Negations

A. Modern and critical approaches
i. Marxism
ii. Liberalism/Constitutionalism/New Governance
iii. Idealist
iv. Critical Theory
v. Feminism
vi. Queer Theory
vii. Postcolonial Theory

B. 'Law and'
i. Law and international relations/political science
ii. Law and economics
iii. Law and sociology
iv. Law and history

Obviously, there are a number of problems with this approach. There are overlaps between the different approaches (for example feminist, queer and postcolonial theories are also 'critical theory'). In real life, legal research projects rarely adopt a pure version of just one theoretical or methodological perspective. Many of the avowedly theoretical approaches have arisen at least in part as a response to earlier theoretical approaches, and thus draw to some extent on those other approaches. Others build upon the

\footnotetext{
1 The idea for the labels of Part I and Part II was taken from Barron et al. (2005) Jurisprudence \& Legal Theory: Commentary and Materials.
} 
insights in other theories (whether they admit it or not). The approaches identified and classified are thus not hermetically sealed, but fluid, and negotiable. Hence, the headings used in the project materials are by no means determinative, and many scholars could equally have been brought under a number of different headings, either because their work spans both areas, or because the labels used do not quite capture the way these scholars approach their studies. The labels used are not intended to be normative, merely a way of grouping people together in a manner which makes introductions, such as those made in the project materials, manageable. The list is supposed to be a device to help EU and international law scholars clarify their thinking, not a straightjacket.

Secondly, it was not possible to include all relevant approaches in the list. The list omits several other interdisciplinary approaches, such as law and geography, law and anthropology, or law and literature. In part, this relates to the prevalence (or lack thereof) of such approaches in EU and international law. The absence of much literature in the area is not, in itself though, a justification for excluding an approach. Indeed the absence of much work on point leaves a great deal of room for innovative work. However, practicalities of how many approaches can be covered in one workshop meant that judgment calls had to be made on inclusions and exclusions, and some can (and will) disagree. The main point of contention was the exclusion of comparative law. This was partly to keep the project manageable, but also justified since, in our view, comparative law is a subject in itself and thus has its own theories and methods. Several of the academic partners to the project were disappointed about this omission. They pointed out that, in both EU and international law scholarship, there is a tradition of using comparative methods (see Lenarets 2003). That is indeed the case. There is therefore scope for a similar project, based on comparative law.

Thirdly, the different approaches on the list are in some senses incommensurable, in that they are trying to achieve different things. For example, legal positivism cannot be rigidly contrasted with critical approaches because they are the methodological bases for seeking answers to different types of research questions. The application of the different approaches to international or EU law has also developed in different ways. Sometimes an abstract pre-existing theory has been applied, 'top-down', to international or EU law. These approaches may be inspired by specific sources, for instance national constitutional legal theories. Alternatively, they may draw on general social science perspectives, for instance discourse analysis, which are used in all sorts of fields, not just legal scholarship. At other times, approaches and theories have developed 'bottom up'. They are grounded in specific substantive questions which researchers have pursued in their legal research projects.

A further important point is that it is difficult to 'label' approaches/methodologies/theories since many proponents do not wish to be labelled as belonging to a certain 'category' of thinking. Moreover, as noted above, labels give the false impression of clear demarcation between approaches, whereas many scholars use more than one approach as and when it serves their purpose.

Nevertheless, the list and its labels provide a useful heuristic device and a means of enhancing communication between the workshop participants. A number of the workshop activities were specifically designed to draw participants' attention to the problems inherent in labels. For instance, groups created a Venn diagram of two of the approaches on the list, noting in particular which ideas, concepts, questions, scholars, and so on, fell within both of their two approaches. 


\section{Practical information}

The project has ten formal partner institutions (Belfast, Birmingham, Durham, Glasgow, Keele, Leicester, Liverpool, Manchester, Nottingham and Sheffield), but the project materials are freely available on the project's website ${ }^{2}$, and the workshops are open to participants from any institution. Although the project is aimed at law students, it welcomes students from all disciplines who are interested in legal research methodologies.

\section{Conclusion}

We hope it has now become clear that the project coordinators have little time for those who use theoretical or methodological discourse to mystify, to inflate weak thinking, or simply to sound clever. The project seeks to show that developing an understanding of different possible theoretical and/or methodological positions which inform international or EU legal research is all about the essentially practical activity of enhancing our capacities as international or EU legal scholars, and improving the outcomes of our research and writing endeavours (including PhD theses).

\section{References}

Barron, A.; Collins, H.; Jackson, E.; Lacey, N.; Reiner, R.; Ross, H.; Teubner, G.; Penner, J.; Schiff D. and Nobles R. (2005). Introduction to Jurisprudence and Legal Theory: Commentary and Materials. Oxford: Oxford University Press.

Lenaerts K. (2003). 'Interlocking Legal Orders in the European Union and Comparative Law', International and Comparative Law Quarterly, 52 (4), pp. 873-906.

\footnotetext{
2 Project website available at:

http://www.sheffield.ac.uk/law/research/clic/research/projects/res methodology
} 